\title{
Rose Bengal and Non-Polar Derivatives: The Birth of Dye Sensitizers for Photooxidation ${ }^{+}$
}

\author{
Joseph J. M. Lamberts and D. C. Neckers* \\ Department of Chemistry, Bowling Green State University, Bowling Green, Ohio 43403, USA \\ Z. Naturforsch. 39b, 474-484 (1984); received October 19, 1983 \\ Rose Bengal Derivatives, Photoxidation \\ The synthesis of a new rose bengal derivative, 6-O-acetyl rose bengal ethyl ester is reported. \\ The spectral properties of various new rose bengal derivatives are discussed in relation to their \\ structures and compared with results found for the other fluorescein dyes in the literature. A \\ concise historical review of the chemistry of fluorescein dyes and of their current applications is \\ given.
}

\section{Introduction}

\subsection{Historical survey and application of the fluorescein dyes}

Rose bengal, $3^{\prime}, 4^{\prime}, 5^{\prime}, 6^{\prime}$-tetrachloro-2,4,5,7-tetraiodouranine (4) was discovered a little over a century ago by Gnehm eleven years after the discovery of its parent molecule, fluorescein $\mathbf{1}$ by Baeyer [1] (Scheme 1). Rose bengal was one of many new dyes discovered near the turn of the century and quickly

Scheme 1.

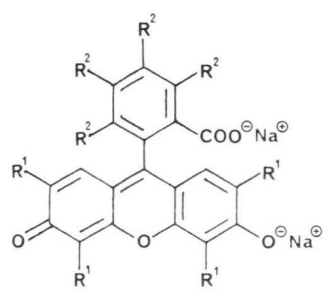

$\mathrm{R}^{1} \quad \mathrm{R}^{2} \quad \lambda_{\max }(\mathrm{nm}) \Phi_{\mathrm{F}} 9 \quad \Phi_{\mathrm{ST}} 9 \quad \Phi_{1_{\mathrm{O}_{2}}} 9 \Phi_{\mathrm{ST}} 52$

$\begin{array}{llllllll}1 \text { uranine* }^{*} & \text { H } & \text { H } & 491 & 0.93 & 0.03 & 0.1 & 0.03\end{array}$

$\begin{array}{llllllll}2 \text { eosin } & \mathrm{Br} & \mathrm{H} & 514 & 0.63 & 0.3 & 0.4 & 0.32\end{array}$

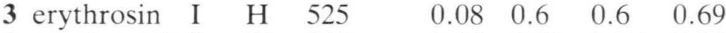

$\begin{array}{llllllll}4 & \text { rose bengal I } & C l & 548 & 0.08 & 0.76 & 0.76 & 0.86\end{array}$

* Uranine is the disodium salt of fluorescein.

* The systematic name of fluorescein in its quinoid form is benzoic acid, 2-(6-hydroxy-3-oxo-3 H-xanthen-9-yl)-

* The systematic name of fluorescein in its lactonic form is spiro[isobenzofuran-1 $(3 \mathrm{H}) \cdot 9^{\prime}$ - $[9 \mathrm{H}]$ xanthen]-3-one. $3^{\prime} \cdot 6^{\prime}$-dihydroxy-

\footnotetext{
This paper is dedicated with sincere friendship to Professor Günther Otto Schenck on the occasion of his 70 th anniversary.

* Reprint requests to Prof. Dr. D. C. Neckers.

0340-5087/84/0400-0474/\$ 01.00/0
}

took on significance both in photobiology and dyesensitized oxygenation. Raab, in 1900, observed that paramecia, when exposed to acridine, were killed only in the presence of light but not in the dark [2]. Later, this process was termed the "photodynamic effect" [3]. In 1931 Kautsky and De Bruijn first proposed that singlet oxygen was the reactive intermediate in dye-sensitized oxygenations [4] though Windaus and Brunken had earlier reported dye-sensitized photooxygenation yielding an isolable peroxide [5]. Subsequently, Kautsky's singlet oxygen was discounted in favor of a mechanism in which the sensitizer was excited to a metastable state having biradical character, the latter reacting with oxygen to form a labile sensitizer-oxygen complex. This complex was then suggested to transfer oxygen to the substrate giving the photooxygenation product $[6,7]$. The first detailed kinetic investigation of dye-sensitized oxygenation was reported by Schenck in 1951 [8], and this was followed by the development of a method for determining the quantum yield of triplet formation of the sensitizer [9]. A procedure based on quenching all dye triplets with $\mathrm{O}_{2}$ and the subsequent trapping of all the singlet oxygen with a very reactive acceptor was developed by Schenck and Gollnick with the reaction rates thus obtained being independent of acceptor concentration. Presently, it is generally accepted that singlet oxygen is the reactive intermediate in dye-sensitized photooxygenation reactions $[10-16]$. Apart from their action as singlet oxygen sensitizers (Type II mechanism) the $n, \pi^{*}$ triplets of the halofluorescein dyes may also interact directly with substrates (Type I mechanism) [17-23]. This often leads to $\mathrm{H}$-transfer or electron transfer, especially with easily oxidizable (phenols, amines) or reducible substrates (quinones) [20-22]. A concomitant dehalogenation of the dye may take place 
[19-21]. Recently, the photodimerization of 2-acyl1,4-benzoquinones in the presence of rose bengal has been reported [24]. The purity of halofluorescein dyes has always presented a major problem. Even recently published chromatographic purification methods are unsatisfactory from a preparative point of view $[25,26]$. Other groups have resorted to preparation of purer dyes through carefully controlled halogenation conditions in the final synthetic step [27].

In addition to their wide application in textile coloring [28] and biological staining [29], the number of studies devoted to the interaction of dyes and biopolymers or living cells is enormous [30] and a fair portion of these deal with the influence of fluorescein dyes, most often rose bengal $\mathbf{4}$, on proteins [31], intact cells [32,33] and, mainly, membranes [34-40]. Erythrosin (3) and rose bengal (4) have also been used successfully in insect control [41-48]. Rose bengal (4) has potential applications in the photochemical treatment of excessive algal growth in water [49] and the degradation of organic phosphate pesticides in waste water for which model studies have been carried out $[50,51]$. In recent years, photodynamic destruction of tumors has experienced a revival with promising results which justify increasing research efforts in the biological activity of the photosensitizing dyes [30].

\subsection{Structure and spectral properties of the fluorescein dyes}

The structures of fluorescein (1) and its halo-derivatives (2-4) are given in Scheme 1 along with their photophysical properties. The longestwavelength absorption band $\left(\lambda_{\max }\right)$ undergoes a redshift when the number of halogen substituents is increased or when heavier halogens are introduced. Scheme 1 also shows the quantum yields of fluorescence $\left(\varnothing_{\mathrm{F}}\right)$, intersystem crossing $\left(\varnothing_{\mathrm{ST}}\right)$, and singlet oxygen formation $\left(\varnothing_{1_{\mathrm{O}_{2}}}\right)$ as determined by Schenck $e t$ al. [9].

A halofluorescein dye is a better singlet oxygen sensitizer when it has a high quantum yield of triplet formation. Triplet yield is directly related to the kind and number of heavy atoms present in the molecule. Recently, the quantum yields of intersystem crossing for these dyes were remeasured [52] after purification of the dyes with modern chromatographic methods [26] (Scheme 1). From these data the outstanding efficiency of rose bengal as singlet oxygen sensitizer compared to the other dyes is obvious.

Numerous studies have aimed at the relationship between the structure of a fluorescein dye and its spectral properties at different pHs. In 1927, Orndorff and Hemmer isolated a yellow and a red form of fluorescein to which they assigned the lactonic 8 and quinoid 6 structures, respectively (Scheme 2) [53]. Zanker and Peter studied the protonation

Scheme 2 .

Protonation equilibria of fluorescein $[53,54]$.

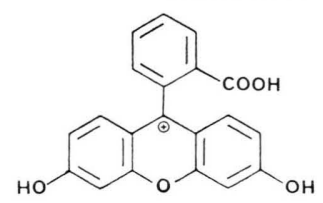

cation $\mathbf{5}$

neutral molecule

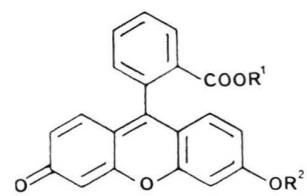<smiles>O=C([O-])c1ccccc1C1c2ccc(O)cc2Oc2cc(O)ccc21</smiles>

$\mathrm{R}^{1}=\mathrm{R}^{2}=\mathrm{H}$ : quinoid 6

$\mathrm{R}^{1}=\mathrm{CH}_{3} ; \mathrm{R}^{2}=\mathrm{H}$ or $\mathrm{Na}$ : methyl ester 9

zwitterionic 7

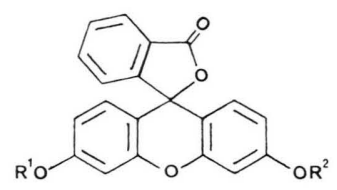

$\mathrm{R}^{1}=\mathrm{R}^{2}=\mathrm{H}$ : lactonic 8

$\mathrm{R}^{1}=\mathrm{R}^{2}=\mathrm{CH}_{3}$ : dimethylether $\mathbf{1 0}$

$\mathrm{R}^{1}=\mathrm{H} ; \mathrm{R}^{2}=\mathrm{CH}_{3}$ : monomethyl ether $\mathbf{1 2}$

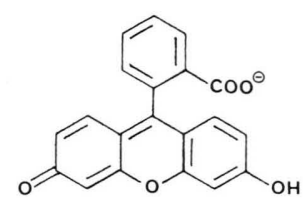

monoanionic $\mathbf{1 3}$

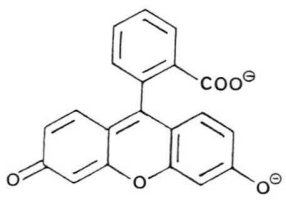

dianionic $\mathbf{1 4}$ equilibria of fluorescein in dioxane and dioxane-water mixtures [54]. The yellow modification of the neutral molecule when dissolved in dioxane gave an 
almost colorless solution, indicating the presence of only lactonic fluorescein $\mathbf{8}$. Gradual addition of water led to a clear increase in intensity in the visible region of the absorption spectrum. This was interpreted as resulting from dissociation of one of the phenolic residues with concomitant ring opening of the lactone leading to formation of the quinoid moiety and a carboxylate anion, i.e., the quinoid monoanion (13). Addition of gradually increasing amounts of ammonia led to a red shift in the longest-wavelength absorption maximum which pointed to the formation of the dianion 14.

On the other hand addition of sulfuric acid to a solution of yellow fluorescein in dioxane led to a new absorption band in the visible region. This was explained by the presence of the cation of fluorescein $\mathbf{5}$. The authors assumed a zwitterionic intermediate $\mathbf{7}$ in the transition from the cation $\mathbf{5}$ to the neutral molecule $\mathbf{6 , 8}$.

More recently, a number of studies have focused on the influence of dye aggregation on the absorption [55-59] and fluorescence spectra [60-63] of fluorescein and its halo-derivatives [64]. Also, the $\mathrm{pH}$-dependence of fluorescein fluorescence has been studied [65] as have the influence of the absence of the 2 '-carboxy function on the photophysical properties of fluorescein in a range of solvents with various hydrogen bonding capacities [66, 67]. The quantum yield of fluorescence was much smaller if the $2^{\prime}$-carboxy group was absent.

Structural studies analogous to those performed on fluorescein have also been carried out for its halogenated derivatives $[68-70]$. The presence of halogen substituents decreases the tendency of fluorescein dyes to be protonated. This may be due to the electron attracting nature of the halogen atoms which increases the acidity of the compounds.

Recently, all three possible modifications of solid fluorescein have been isolated, a red quinoid $\mathbf{6}$, a colorless lactonic form $\mathbf{8}$, and a yellow zwitterionic form 7 [71] (Scheme 2). The quinoid form 6 was characterized by a $v_{\mathrm{C}=\mathrm{O}}$ at $1711 \mathrm{~cm}^{-1}$ corresponding to the carboxylic acid group. In $\mathbf{8}$ a $v_{\mathrm{C}=\mathrm{O}}$ was found at $1730 \mathrm{~cm}^{-1}$ for the lactone. In 7 no $v_{\mathrm{C}=\mathrm{O}}$ was observed above $1600 \mathrm{~cm}^{-1}$, but an absorption was found at $1596 \mathrm{~cm}^{-1}$ characteristic for pyrylium salts. These last data suggested the zwitterionic structure 7 for the yellow solid. In water the colorless form changed easily to the yellow form. All three solid forms had distinct and definite X-ray powder patterns.
Scheme 3. The X-ray structures of the 1:1 complex of acetone and the lactonic form of fluorescein $\mathbf{1 5}$ and of the perchlorate of fluorescein $\mathbf{1 6 .}$

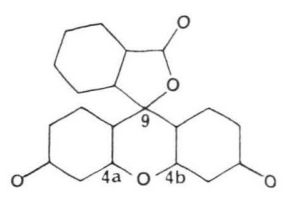

15

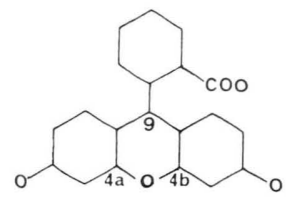

16
Only two other X-ray studies have been published on fluorescein dyes $[72,73]$. The first reports on the crystal structure of a 1:1 complex of acetone and the lactonic form of fluorescein $\mathbf{1 5}$ (Scheme 3) [72]. The lactone - aromatic ring was found to be nearly perpendicular to the rest of the molecule. The bond between $\mathrm{C}(9)$ of the xanthene and the lactone $\mathrm{O}$ is exceptionally long $(1.525 \AA)$ and indicates a weakness which corresponds to the behavior of the lactone in solution where ready cleavage of the $\mathrm{C}-\mathrm{O}$ bond yields the zwitterionic form. The authors describe opening to two tautomeric zwitterions: one with the positive charge on the xanthene $\mathrm{O}$-atom and the other with the positive charge on $\mathrm{C}(9)$. The structures shown in their paper however, correspond to two mesomeric structures of the same compound,

The X-ray structure of the perchlorate of fluorescein $\mathbf{1 6}$ is also reported (Scheme 3) [73]. The three rings in the xanthene moiety in this system were found to be coplanar, which corresponds to a protonated fluorescein molecule with delocalization of the positive charge over the entire xanthene system. These authors pointed out the much shorter bonds $\mathrm{C}(4 \mathrm{a})-\mathrm{O} \quad(1.33 \AA)$ and $\mathrm{C}(4 \mathrm{~b})-\mathrm{O}(1.32 \AA)$ in fluorescein perchlorate $\mathbf{1 6}$ compared to the same bonds in the lactone $\mathbf{1 5}(1.50 \AA)$. However, probably because of the different numbering of atoms in both articles, comparison was made with the wrong bonds, their actual values in the lactone being $\mathrm{C}(4 \mathrm{a})-\mathrm{O}(1.378 \AA)$ and $\mathrm{C}(4 \mathrm{~b})-\mathrm{O}(1.377 \AA)$ so that the effect is qualitatively the same but much less extreme (Scheme 3).

Interesting as well are the results of Chen et al. who compared the protonation equilibria and the absorption and fluorescence spectra of fluorescein in aqueous solution with those of its methyl ester $\mathbf{9}$, its monomethyl ether $\mathbf{1 1}, \mathbf{1 2}$ and its dimethyl ether $\mathbf{1 0}$ (Scheme 2) [74]. The methyl ester 9 cannot assume the lactonic form, since the carboxylic acid function 


$$
\begin{array}{llll}
\mathrm{Fl} & \mathrm{FlEt} & \mathrm{Eo} & \mathrm{EoEt} \\
\mathrm{nr} . \quad \lambda_{\max }(\mathrm{nm}) \mathrm{nr} . \quad \lambda_{\max }(\mathrm{nm}) \mathrm{nr} . \quad \lambda_{\max }(\mathrm{nm}) \mathrm{nr} . \quad \lambda_{\max }(\mathrm{nm})
\end{array}
$$

\begin{tabular}{lrrrrrrrr} 
cation & $\mathbf{5}$ & 438 & $\mathbf{1 7}$ & 442 & $\mathbf{2 0}$ & 453 & $\mathbf{2 4}$ & 455 \\
neutral & $\mathbf{6}$ & 454 & $\mathbf{1 8}$ & 458 & $\mathbf{2 1}$ & 479 & $\mathbf{2 5}$ & 480 \\
monoanion & $\mathbf{1 3}$ & 460 & $\mathbf{1 9}$ & 499.5 & $\mathbf{2 2}$ & 518 & $\mathbf{2 6}$ & 529 \\
dianion & $\mathbf{1 4}$ & 490 & - & - & $\mathbf{2 3}$ & 515 & $\mathbf{2 7}$ & - \\
\hline
\end{tabular}

Tab. I. Longest-wavelength absorption maxima of fluorescein $(\mathrm{Fl})$, eosin (Eo) and their respective ethyl esters (FIEt, EoEt) in their various ionization states [75]. The structures of the cation, the neutral form and the dianion are comparable to structures 5, 6 and 14 respectively in Scheme 2. The structure of the monoanion of FlEt (19), Eo (2) and EoEt (26) is shown below in Scheme 4. The numbers shown are used as a reference in the text.
Scheme 4.<smiles>[R]C(=O)c1ccccc1-c1c2cc([R])c(=O)c([R])c-2oc2c([R])c([O-])c([R])cc12</smiles>

19: $\mathrm{R}^{1}=\mathrm{H} ; \mathrm{R}^{2}=\mathrm{Et}$

22: $\mathrm{R}^{1}=\mathrm{Br} ; \mathrm{R}^{2}=\mathrm{H}$

26: $\mathrm{R}^{1}=\mathrm{Br} ; \mathrm{R}^{2}=\mathrm{Et}$

is blocked, whereas $\mathbf{1 0}$ is only present in the lactonic form. The monomethyl ether can occur in both the quinoid $\mathbf{1 1}$ and the lactonic form 12. This study led to the conclusion that no neutral quinoid form $\mathbf{6}$ of fluorescein exists in aqueous solution. Below $\mathrm{pH} 1$ fluorescein was predominantly present as $\mathbf{5}$, at $\mathrm{pH} 3$ as $\mathbf{8}$, at $\mathrm{pH} \mathrm{5-6}$ as $\mathbf{1 3}$ and at pH 8 as $\mathbf{1 4}$ (Scheme 2).

Important results have been obtained in recent studies comparing the protonation equilibria of fluorescein and eosin [75, 76]. It was observed that, starting at the cation of fluorescein $\mathbf{5}$ and gradually going to higher $\mathrm{pH}$, the absorption maximum underwent consecutively a large, a small and a large red shift corresponding to the formation of the neutral molecule 6, the monoanion 13 and the dianion 14, respectively (Table I). This conclusion was based on the notion that ionization of the phenol residues of the xanthene moiety has the largest influence on the position of the absorption maximum in the visible region of the spectrum, whereas the ionization of the carboxylic acid function will have little influence. This is in agreement with the plane of the phenyl substituent at $C(9)$ being almost perpendicular to the plane of the xanthene moiety and both moieties therefore not being conjugated to one another. A comparison was made with the protonation equilibria in fluorescein ethyl ester, in which only the two large redshifts are observed $(\mathbf{1 7} \rightarrow \mathbf{1 8} \rightarrow \mathbf{1 9})$.

The situation was slightly different for eosin. Beginning with its cation 20, two large red-shifts are observed $(\mathbf{2 0} \rightarrow \mathbf{2 1} \rightarrow \mathbf{2 2})$, followed by a small blueshift $(\mathbf{2 2} \rightarrow \mathbf{2 3})$. From the observed shifts in the absorption maximum it is concluded that the phenol function in eosin is more acidic than the carboxylic acid function and that therefore in the monoanion of eosin the phenolate has been formed whereas the carboxylic acid is un-ionized in $\mathbf{2 2}$ as opposed to the situation in fluorescein monoanion 13 (Scheme 4). These results were again compared to those of eosin ethyl ester where, starting from the cation $\mathbf{2 4}$, only two large red-shifts are observed $(\mathbf{2 4} \rightarrow \mathbf{2 5} \rightarrow \mathbf{2 6})$.

This important difference in the behavior of the phenolic residues of fluorescein and eosin is undoubtedly the consequence of the presence of the electron attracting bromine atoms in eosin which facilitate the delocalization of the negative charge in the phenolate, thereby enhancing the acidity in the xanthene-phenol function vs. that in fluorescein.

The authors do not allow for a zwitterionic form of fluorescein $\mathbf{7}$ in aqueous solution as was suggested by Markuszewski et al. [71].

In a second article by the same authors the structures of fluorescein and eosin were studied in the solid state and in several organic solvents [77]. For the lactonic structure of fluorescein a $v_{\mathrm{C}=\mathrm{O}}$ was found at $1730 \mathrm{~cm}^{-1}$ in the IR spectrum, which is in agreement with the figure found by Markuszewski et al., but which was considered unusually low for a lactone. It was argued that the presence of two free hydroxyl groups at $\mathrm{C}(3)$ and $\mathrm{C}(6)$ destabilizes the lactone, an observation in agreement with the X-ray spectrum [72], and this was demonstrated by acetylation of these functions which shifted the $v_{\mathrm{C}=\mathrm{O}}$ to $1760 \mathrm{~cm}^{-1}$. For eosin lactone the corresponding figures were $1755 \mathrm{~cm}^{-1}$ and for the diacetyl derivative $1780 \mathrm{~cm}^{-1}$, indicating that eosin lactone is more stable than that of fluorescein.

Studies in solution led to the conclusion that an equilibrium exists between the lactonic and "am- 
photeric" forms of fluorescein and eosin in solution, a point that has been the subject of much discussion in the past. It turned out that the lactonic ring of eosin was less stable than that of fluorescein in organic solvents, as opposed to the situation in water and in the solid state.

At this point it is interesting to notice that, although the results of Fompeydie et al. [75] do not allow for a neutral zwitterionic form $\mathbf{7}$ of fluorescein in solution, because of the higher acidity of the phenolic $\mathrm{OH}$ in the cation 5, Markuszewski et al. [71] have isolated a zwitterionic modification.

\section{The Present Investigation}

Rose bengal is commercially available as its disodium salt and as such it is soluble only in polar solvents such as water and methanol. This limits its use in photooxygenation since, for optimum effectiveness, both the substrate and the dye must be soluble in the solvent required*. Furthermore, rose bengal bleaches when used in oxidation processes over extended periods.

It was the intention when the current work began to study both of these problems; namely solubility, which had been partially overcome in our laboratories previously with polymer-bound rose bengal where a hydrophobic polymeric support provided non-polar solvent compatibility and resistance to bleaching $[78,79]$. Though polystyrene-co-divinylbenzene supports provide a hydrophobic immobilization center for rose bengal and these immobilized dyes are more stable to oxidative bleaching, their quantum yield of singlet oxygen formation is also lower $\left(\emptyset_{1_{0}}=0.43\right)$.

The original polymer-bound rose bengal was prepared from chloromethylated Bio-Beads using the following reaction [78].

Scheme 5. Reaction of rose bengal with chloromethylated polystyrene-co-divinylbenzene.

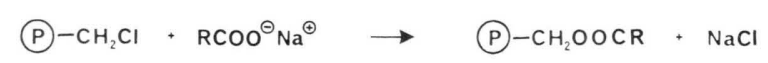

In our original publication we assumed that chloromethylated styrene-divinylbenzene copolymer beads were converted to a rose bengal ester deriva-

* Quantum yields for formation of singlet oxygen from rose bengal in pentane are $10^{-6}$; i.e., undetectable tive based on evidence that the polymer immobilized dye could be partially removed from the support by treatment with dilute base. However, since the phenolate function of rose bengal is also nucleophilic, it was realized that it might displace chloride from the chloromethyl center of the polymer in DMF and the rose bengal may also be attached to the polystyrene as a phenyl ether.

It is the purpose of this report to establish the point of attachment of rose bengal to poly(styreneco-divinyl-benzene) beads in which the immobilization reaction is carried out by a nucleophilic displacement on a chloromethylated derivative (Scheme 5). It was also our intention to prepare monomeric rose bengal derivatives which combine the capacity to produce high triplet yields (for energy transfer to dioxygen) with non-polar solvent compatibility. It has turned out that in order to determine both the point of attachment of the polymer to the dye, and to synthesize soluble derivatives of the rose bengal, we have had to firmly establish the structural characteristics of this rather complicated molecule both in the solid form and in solution.

The reactions with chloromethylated Bio-Beads were therefore repeated with certain alkyl halides to determine, in model studies, whether it is possible to block both the carboxylate and phenolate function of the dye and which of the two centers is more nucleophilic. Furthermore, the influence of this blocking on the absorption spectrum of rose bengal has been studied and the results compared with those reported in the literature for both eosin and fluorescein [75]. The rose bengal derivatives whose properties are described in this paper have not been prepared previously.

\section{Results and Discussion}

\subsection{Esterifications of rose bengal}

Rose bengal (4) was heated in DMF with 1.5 eq of benzyl chloride as a model for the reaction with chloromethylated styrene-divinylbenzene copolymer used to prepare polymer supported rose bengal [78]. The deep purple product $\mathbf{2 8}$ turned out to be insoluble in $\mathrm{CH}_{2} \mathrm{Cl}_{2}$ and showed a $v_{\mathrm{C}=\mathrm{O}}$ at $1730 \mathrm{~cm}^{-1}$ which may point to either an ester function [80] or to a nondissociated polychlorinated benzoic acid [81]. The absorption spectrum in $\mathrm{MeOH}$ had the same shape as that of $\mathbf{4}$ with a small red-shift of $6 \mathrm{~nm}$ compared to 4. Fompeydie et al. noticed a small blue shift on 
changing the $\mathrm{pH}$ of a solution of eosin in water from 3.6 to 8.0 which they ascribed to ionization of the carboxylic acid function [75]. Similarly, conversion of the carboxylic anion of rose bengal into an ester function might lead to the observed shift of $\lambda_{\max }$ in the other direction.

Since the reaction conditions used in the experiment above do not provide sufficient benzyl chloride to convert both anionic centers of rose bengal into an ester and an ether function, respectively, the same experiment was also carried out with 2.5 eq of benzyl chloride. The intention was to synthesize a rose bengal derivative soluble in non-polar solvents; however, the product was poorly soluble in $\mathrm{CH}_{2} \mathrm{Cl}_{2}$ and had the same absorption and IR spectrum as the preceding product. These data suggest that the phenolate anion of rose bengal may not be sufficiently nucleophilic to function as a displacing group at least with benzyl chloride. We believe delocalization of the negative charge decreases the reactivity such that there is no reaction even with an alkyl chloride carrying a highly polarized $\mathrm{C}-\mathrm{Cl}$ bond like benzyl chloride. Both products were of identical elemental analysis and indicated incorporation of only one benzyl group.

The reaction was also carried out in an acetonewater mixture $(50 \% \mathrm{v} / \mathrm{v})$ with $2.5 \mathrm{eq}$ of benzyl chloride [82]. This afforded a bright orange-red product soluble in $\mathrm{CH}_{2} \mathrm{Cl}_{2}$. The IR spectrum showed a $v_{\mathrm{O}-\mathrm{H}}$ at $3410 \mathrm{~cm}^{-1}$ and a $v_{\mathrm{C}=\mathrm{O}}$ at $1730 \mathrm{~cm}^{-1}$. The UV spectrum in $\mathrm{MeOH}$ (red solution) showed a $\lambda_{\max }$ at $564 \mathrm{~nm}$ with a shoulder at $524 \mathrm{~nm}$, the same spectrum as the samples prepared in DMF. In $\mathrm{CH}_{2} \mathrm{Cl}_{2}$, however, (bright orange-red solution) there were maxima at $494 \mathrm{~nm}$ and $407 \mathrm{~nm}$. In several literature reports it has been pointed out that the plane of the $2^{\prime}$-carboxyphenyl substituent at $\mathrm{C}(9)$ of the xanthene moiety of fluorescein dyes is perpendicular to the plane of the xanthene ring system and the latter is largely responsible for the absorption characteristics of the molecule in the visible region $[65,66,72,73$,
77]. Therefore, upon a change of solvent from $\mathrm{MeOH}$ to $\mathrm{CH}_{2} \mathrm{Cl}_{2}$ a major change takes place in the xanthene portion. Since the original reaction was carried out in the presence of water, the benzyl chloride may partially hydrolyze to benzyl alcohol and $\mathrm{HCl}$. Assuming that reaction of the carboxylate anion of rose bengal with benzyl cloride is faster than hydrolysis, the order of events is esterification of the carboxylate function followed by protonation of the phenolate anion of rose bengal. This form of rose bengal benzyl ester (30) was therefore soluble in $\mathrm{CH}_{2} \mathrm{Cl}_{2}$ while the monosodium salt of rose bengal benzyl ester (28) is not. Thus $\mathbf{2 8}$ is the product of benzylations in DMF. This also explains the $v_{\mathrm{O}-\mathrm{H}}$ at $3410 \mathrm{~cm}^{-1}$ in the IR spectrum of $\mathbf{3 0}$. The change in the absorption spectrum by changing the solvent from $\mathrm{CH}_{2} \mathrm{Cl}_{2}$ to $\mathrm{MeOH}$ can be explained by dissociation of the phenolic- $\mathrm{O}-\mathrm{H}$ bond in the more polar solvent. This is not surprising because of the high acidity of this proton. The phenolic proton of eosin is also more acidic than that of fluorescein [75]. Additional structural proof was obtained by addition of a few drops of concentrated $\mathrm{HCl}$ to a solution of $\mathbf{2 8}$ in $\mathrm{MeOH}$. This made the absorption spectrum of this solution the same as that of $\mathbf{3 0}$ dissolved in $\mathrm{CH}_{2} \mathrm{Cl}_{2}$. The higher proton concentration thus prevents dissociation to the anion. These results were confirmed by repeating the esterification reaction with ethyl iodide in acetone $/ \mathrm{H}_{2} \mathrm{O}$ with eosin 2 and comparing the resulting ester $\mathbf{2 5}$ with an acidified sample of commerically available eosin ethyl ester (monosodium salt) (26). The spectral data for the rose bengal and eosin derivatives are tabulated in Table II.

\subsection{6-O-Acetyl rose bengal ethyl ester (32)}

The results above clearly show that, in order to obtain a rose bengal derivative soluble in $\mathrm{CH}_{2} \mathrm{Cl}_{2}$, it is essential to block both the carboxylate and the phenolate functions of the dye. The benzyl ester prepared in aqueous acetone satisfies this condition but

Table II. Spectral data for the rose bengal and eosin derivatives $\left(v_{\mathrm{C}=\mathrm{O}}\right.$ in $\mathrm{KBr}$ and $\lambda_{\max }$ in $\left.\mathrm{MeOH}\right)$.

\begin{tabular}{lccccrr}
\hline & \multicolumn{2}{c}{ rose bengal } & & \multicolumn{2}{c}{$\operatorname{eosin}$} \\
& $\mathrm{nr}$. & $v_{\mathrm{C}=\mathrm{O}}\left(\mathrm{cm}^{-1}\right)$ & $\lambda_{\max }(\mathrm{nm})$ & $\mathrm{nr}$. & $v_{\mathrm{C}=\mathrm{O}}\left(\mathrm{cm}^{-1}\right)$ & $\lambda_{\max }(\mathrm{nm})$ \\
\hline disodium salt & $\mathbf{4}$ & - & 558,519 & $\mathbf{2}$ & - & 526,494 \\
ethyl ester, monosodium salt & $\mathbf{2 9}$ & 1730 & 564,524 & $\mathbf{2 6}$ & 1710 & 531,498 \\
6-O-acetyl-, ethyl ester & $\mathbf{3 2}$ & 1780,1730 & 494,395 & $\mathbf{3 5}$ & 1780,1710 & 474,367 \\
\hline
\end{tabular}


the compound does not have a unique structure in solution. Since the acidic character of this derivative could also interfere with its action as a singlet oxygen sensitizer, especially in connection with the synthesis of hydroperoxides which are sensitive to acids, it was necessary to block the phenolate function permanently. The O-acetyl derivative was thus synthesized by refluxing with acetic anhydride. To our surprise, this reaction did not yield the expected orange-red 6O-acetyl rose bengal-benzyl ester but, instead, the colorless diacetyl derivative of the lactonic modification of rose bengal which was indicated by the disappearance of the IR-absorption at $1730 \mathrm{~cm}^{-1}$. This was proved by precipitation of rose bengal lactone (34) by addition of concentrated $\mathrm{HCl}$ to an aqueous solution of rose bengal and converting the product to 3.6-diacetyl rose bengal lactone (33) by refluxing with acetic anhydride [53] (Scheme 6). Both 33 and

Scheme 6. Reaction of rose bengal benzylester with acetic anhydride.
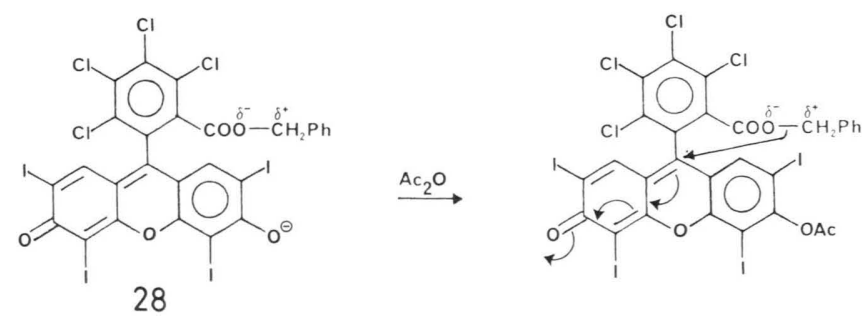

28
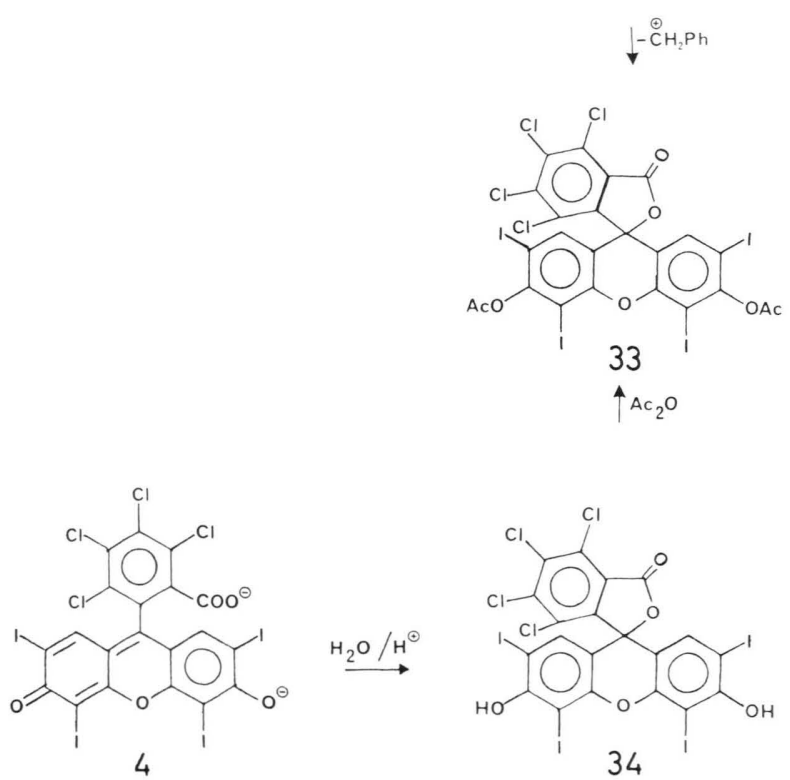

34 are nearly colorless compounds soluble in $\mathrm{CH}_{2} \mathrm{Cl}_{2}$ having no absorption in the visible region in $\mathrm{CH}_{2} \mathrm{Cl}_{2}$ but a strong IR absorption band at $1770 \mathrm{~cm}^{-1}$ for $\mathbf{3 4}$ corresponding to the lactone $\mathrm{C}=\mathrm{O}$ function and at $1780 \mathrm{~cm}^{-1}$ for 33 corresponding to the lactone $\mathrm{C}=\mathrm{O}$ function and the acetyl $\mathrm{C}=\mathrm{O}$ function. The absorption-spectrum of $\mathbf{3 4}$ in $\mathrm{MeOH}$ was the same as that of rose bengal indicating complete dissociation and presence as the quinoid modification, whereas that of $\mathbf{3 3}$ was the same in both $\mathrm{MeOH}$ and in $\mathrm{CH}_{2} \mathrm{Cl}_{2}$.

The explanation of this phenomenon is the high polarity of the methylene-C-O bond in the benzyl ester, especially in a polar solvent. Upon introduction of the first acetyl function at the 6-O position the double bond character of the $3-\mathrm{C}=\mathrm{O}$ bond will increase, but the $3-\mathrm{O}$ will still have sufficient nucleophilic character to attack acetic anhydride when aided by an electron-push caused by attack of the ester-O on the slightly positively charged $C(9)$ with simultaneous elimination of benzyl cation.

It was anticipated that this elimination, which was undesired, could be prevented by converting the rose bengal carboxylate to a different ester, which has a less polarized $\mathrm{C}-\mathrm{O}$ bond, e.g. ethyl ester. This reaction was carried out using ethyl iodide in $50 \% \mathrm{v} / \mathrm{v}$ aqueous acetone. The product, rose bengal ethyl ester, has the same IR and absorption characteristics as the benzyl ester. When refluxed with acetic anhydride the bright red colored 6-O-acetyl-rose bengal ethyl ester was obtained. This showed no $v_{\mathrm{O}-\mathrm{H}}$ in the IR spectrum, but $v_{\mathrm{C}=0}$ at $1780 \mathrm{~cm}^{-1}$ and $1730 \mathrm{~cm}^{-1}$ for the acetyl and carboxylate ester groups respectively. The absorption spectrum was the same in $\mathrm{MeOH}$ and $\mathrm{CH}_{2} \mathrm{Cl}_{2}$ and had maxima at $494 \mathrm{~nm}$ and $395 \mathrm{~nm}$. The spectrum looked qualitatively similar to the absorption spectrum of rose bengal benzyl ester or ethyl ester in $\mathrm{CH}_{2} \mathrm{Cl}_{2}$. To obtain additional confirmation of the structure the acetylation was repeated with commercial ethyl eosin (26); this afforded 6-Oacetyl eosin ethyl ester $\mathbf{3 5}$ with an IR spectrum very similar to that of $\mathbf{3 2}$ and an absorption spectrum qualitatively the same as $\mathbf{3 2}$ (Table II).

Scheme 7 shows the absorption spectra of the synthesized rose bengal derivatives in relation to their structures. The protonation of the xanthene phenolate function has a dramatic influence on the shape of the absorption spectrum causing a blue shift of $70 \mathrm{~nm}$ in the longest-wavelength absorption maximum. Protonation of the carboxylate group only leads to a small red shift of $6 \mathrm{~nm}$ (in $\mathrm{MeOH}$ ). The 
Scheme 7. The structures of the synthesized rose bengal derivatives and their corresponding visible absorption spectra.

The intention is to give an impression of the shape of the spectra. For exact data, see the Experimental Section.<smiles>O=C([O-])c1c(Cl)c(Cl)c(Cl)c(Cl)c1-c1c2cc(I)c(=O)c(I)c-2oc2c(I)c([O-])c(I)cc12</smiles>

dianionic

4 rose bengal<smiles>O=C(O)c1c(Cl)c(Cl)c(Cl)c(Cl)c1-c1c2cc(I)c(=O)c(I)c-2oc2c(I)c([O-])c(I)cc12</smiles>

monoanionic

$28 \mathrm{R}=-\mathrm{CH}_{2} \mathrm{Ph}$ : rose bengal benzyl ester

$29 \mathrm{R}=-\mathrm{Et}$ : rose bengal ethyl ester<smiles>[R]Oc1c(I)cc2c(-c3c(Cl)c(Cl)c(Cl)c(Cl)c3C(=O)O)c3cc(I)c(=O)c(I)c-3oc2c1I</smiles>

neutral

$30 \mathrm{R}^{1}=\mathrm{CH}_{2} \mathrm{Ph} ; \mathrm{R}^{2}=\mathrm{H}$ rose bengal benzyl ester,

$31 \mathrm{R}^{1}=\mathrm{Et} ; \mathrm{R}^{2}=\mathrm{H}$ molecular form rose bengal ethyl ester, molecular form

$32 \mathrm{R}^{1}=\mathrm{Et} ; \mathrm{R}^{2}=\mathrm{Ac}$
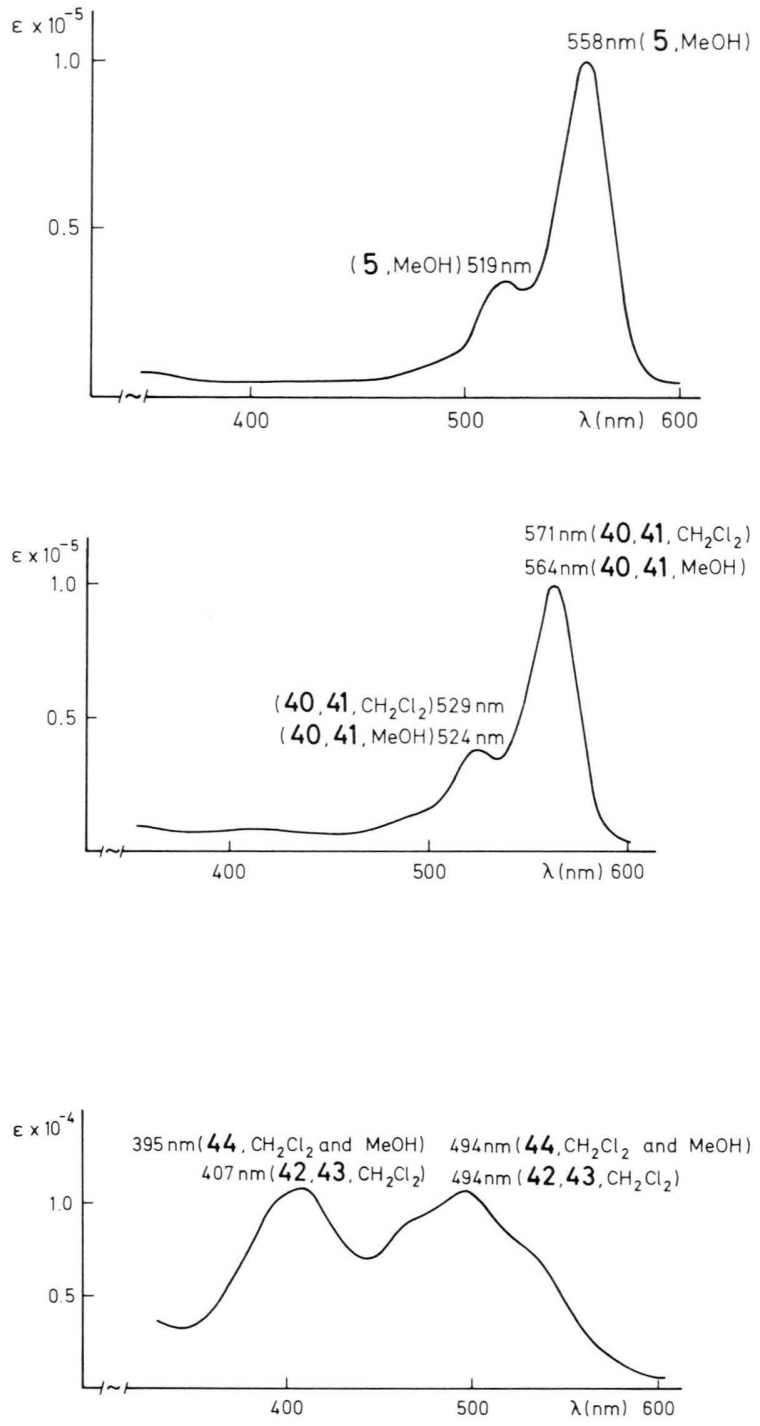

molecular forms of rose bengal benzyl and ethyl ester have a different absorption spectrum in $\mathrm{MeOH}$ and $\mathrm{CH}_{2} \mathrm{Cl}_{2}$. These samples in the solid state have the same color as the solution in $\mathrm{CH}_{2} \mathrm{Cl}_{2}$. The solution of these samples in $\mathrm{MeOH}$ is red and the absorption spectrum identical to that of rose bengal benzyl or ethyl ester (monosodium salt). Apparently, dissociation of the xanthene-phenol function occurs in the more polar solvent.
Comparison of the series 6-O-acetyl rose bengal ethyl ester (32) (494 $\mathrm{nm})$, rose bengal ethyl ester (monosodium salt) (29) (564 nm) and rose bengal (4) $(558 \mathrm{~nm})$ on the one hand and 6-O-acetyl-ester (35) (474 nm), eosin, ethyl ester (monosodium salt) (26) $(531 \mathrm{~nm})$ and eosin $(2)(526 \mathrm{~nm})$ shows that the evolution of the absorption spectrum with the blocking of the carboxylate and phenolate group is qualitatively the same in both series and comparable to the 
results of Fompeydie et al. [75] (Table II). Furthermore, a 6-O-monoester of fluorescein described in a recent publication had an absorption spectrum with exactly the same shape as $\mathbf{3 2}$, only shifted to shorter wavelengths [83].

Preliminary experiments have shown that 6-Oacetyl-rose bengal ethyl ester is a singlet oxygen sensitizer in dichloromethane. The scope and efficiency of this rose bengal derivative in this and other nonpolar solvents is under active investigation.

\section{Experimental Section}

\subsection{General}

Rose bengal, dye content $92 \%$, and eosin ethyl ester (monosodium salt), dye content 98\%, were purchased from the Aldrich Co., Milwaukee, and eosin Y, dye content 93\%, from Eastman, Rochester. The commercial products were used in synthesis without prior purification. ${ }^{1} \mathrm{H}$ NMR spectra were measured on a Varian CFT-20 79.6 MHz ${ }^{1} \mathrm{H}$ NMR spectrometer in $\mathrm{CDCl}_{3}$ with TMS as internal standard. Chemical shifts are given in $\delta(\mathrm{ppm})$ and $J$-values are expressed in $\mathrm{Hz}$. Infrared spectra were obtained using a Perkin-Elmer 337 grating IR spectrophotometer and UV spectra using a Varian Cary 219 instrument. Melting points were measured on a Thomas-Hoover capillary melting point apparatus. Elemental analyses were performed by Galbraith Laboratories, Inc., Knoxville, Tennessee, and all values were in the expected range.

\section{Synthetic Procedures}

\subsection{Rose bengal (lactone) (34)}

Rose bengal (4) $1.02 \mathrm{~g}$; $1 \mathrm{mmol}$ ) was dissolved in water $(25 \mathrm{ml})$ and concentrated $\mathrm{HCl}(1 \mathrm{ml})$ was added dropwise. A red precipitate was formed. Another $25 \mathrm{ml}$ of water were added along with $4 \mathrm{ml}$ of concentrated $\mathrm{HCl}$. The resulting slurry was stirred for $30 \mathrm{~min}$, filtered and thoroughly washed with water to remove all excess $\mathrm{HCl}$. The red residue was dried at $80^{\circ} \mathrm{C}$ in a vacuum oven over night. After drying, the compound had a very light pink color. Isolated yield $0.77 \mathrm{~g}(80 \%)$.

IR $(\mathrm{KBr}) 3430 \mathrm{~cm}^{-1}$ (phenolic $\left.\mathrm{OH}\right), 1770 \mathrm{~cm}^{-1}$ (lactone $\mathrm{C}=\mathrm{O}$ ).

UV-Vis $(\mathrm{MeOH}) \lambda_{\max }(\log \varepsilon) 558 \mathrm{~nm}(5.02), 519$ (4.51), $320(4.05) 210(4.76) ; \lambda_{\min }(\log \varepsilon) 528 \mathrm{~nm}$ (4.47).

UV $\left(\mathrm{CH}_{2} \mathrm{Cl}_{2}\right) \lambda_{\max }(\log \varepsilon) 246 \mathrm{~nm}$ (4.76); $\lambda_{\min }$ $(\log \varepsilon) 236 \mathrm{~nm}(4.68)$.

\subsection{3,6-O, $O^{\prime}$-Diacetyl rose bengal (33)}

A mixture of rose bengal lactone (34) $(0.5 \mathrm{~g}$; $0.49 \mathrm{~mol}$ ) and $2.5 \mathrm{~g}$ of acetic anhydride was refluxed over night. The solvent was removed in vacuo and the residue was stirred with ether for $1 \mathrm{~h}$. The precipitate was filtered off, washed with ether and dried at $80{ }^{\circ} \mathrm{C}$ in a vacuum oven overnight.

IR $(\mathrm{KBr}) 1780 \mathrm{~cm}^{-1}$ (lactone $\left.\mathrm{C}=\mathrm{O}\right)$.

The absorption spectrum is qualitatively the same as that of rose bengal lactone (34) in $\mathrm{CH}_{2} \mathrm{Cl}_{2}$. It is, however, the same if taken in $\mathrm{MeOH}$ in this case.

\subsection{Rose bengal benzyl ester, monosodium salt (28) [78]}

Rose bengal (4) (1.58 g; $1.55 \mathrm{mmol})$ was dissolved in $60 \mathrm{ml}$ of dry DMF and benzyl chloride $(0.28 \mathrm{~g}$; $2.22 \mathrm{mmol}$ ) was added. This solution was stirred magnetically and heated over night at an oil-bath temperature of $80{ }^{\circ} \mathrm{C}$. The excess benzyl chloride and DMF were then distilled off in vacuo and the residue was stirred with ether for $1 \mathrm{~h}$. The resulting mixture was filtered and thoroughly washed with ether. A deep purple powder was isolated. It had no distinct melting point.

IR $(\mathrm{KBr}) 1730 \mathrm{~cm}^{-1}$ (ester $\left.\mathrm{C}=\mathrm{O}\right)$.

UV-Vis $(\mathrm{MeOH}) \lambda_{\max }(\log \varepsilon) 564 \mathrm{~nm}$ (5.01), $524 \mathrm{~nm}$ (4.50), 210 (4.83); $\lambda_{\min }(\log \varepsilon) 534 \mathrm{~nm}(4.46)$.

$\mathrm{UV}-\mathrm{V}$ is $\left(\mathrm{CH}_{2} \mathrm{Cl}_{2}\right) \lambda_{\text {max }} 572 \mathrm{~nm}, 529 ; \lambda_{\min } 543 \mathrm{~nm}$.

Solubility in $\mathrm{CH}_{2} \mathrm{Cl}_{2}$ was not sufficient to measure a quantitative absorption spectrum.

\subsection{Rose bengal benzyl ester, molecular form (30) [82]}

Rose bengal (4) (1.02 g; $1 \mathrm{mmol})$ was dissolved in $10 \mathrm{ml}$ of water and a solution of benzyl chloride ( $0.32 \mathrm{~g} ; 2.5 \mathrm{mmol})$ in $10 \mathrm{ml}$ of acetone was added. The resulting solution was refluxed over night. After cooling an orange-red precipitate formed which was filtered off and dried overnight at $80^{\circ} \mathrm{C}$ in a vacuum oven. The orange-red powder was then washed with ether and again dried over night at $80^{\circ} \mathrm{C}$. Yield $0.87 \mathrm{~g}(82 \%)$. It has no distinct melting point, but at $220^{\circ} \mathrm{C}$ the compound is transformed into a dark oil.

IR $(\mathrm{KBr}) 3415 \mathrm{~cm}^{-1}$ (phenolic $\mathrm{OH}$ ), 1730 (ester $\mathrm{C}=\mathrm{O}$ ).

$\mathrm{UV}-\mathrm{V}$ is $\left(\mathrm{CH}_{2} \mathrm{Cl}_{2}\right) \lambda_{\max }(\log \varepsilon) 496 \mathrm{~nm}$ (4.19), 407 (4.19); $\lambda_{\min }(\log \varepsilon) 443 \mathrm{~nm}(4.00), 345$ (3.70).

$\mathrm{UV}-\mathrm{V}$ is $(\mathrm{MeOH}) \lambda_{\max } 564 \mathrm{~nm}, 524$.

The sample was too insoluble in $\mathrm{MeOH}$ to measure a quantitative absorption spectrum.

${ }^{1} \mathrm{H}$ NMR $\left(\mathrm{CDCl}_{3}\right) \delta(\mathrm{ppm}): 5.03(\mathrm{~s}, 2 \mathrm{H}$ benzyl $\left.\mathrm{CH}_{2}\right), 6.82-7.49$ (m, $7 \mathrm{H}$, arom.) 


\subsection{Rose bengal ethyl ester, molecular form (31) [82]}

This compound was synthesized analogous to the benzyl ester, but using, instead, 5 eq. of ethyl iodide.

With a smaller excess of EtI, a band in the IR spectrum was found corresponding to lactonic $\mathrm{C}=\mathrm{O}$. Yield $83 \%$.

IR $(\mathrm{KBr}) 3400 \mathrm{~cm}^{-1}$ (phenolic OH), 1730 (ester $\mathrm{C}=\mathrm{O})$.

Absorption spectra in $\mathrm{MeOH}$ and $\mathrm{CH}_{2} \mathrm{Cl}_{2}$ similar to the benzylester.

\subsection{6-O-Acetyl rose bengal ethyl ester (32) [53]}

A solution of rose bengal ethyl ester, molecular form $(0.5 \mathrm{~g} ; 0.50 \mathrm{mmol})$ in $2.5 \mathrm{~g}$ of acetic anhydride was refluxed over night and the solvent was distilled off in vacuo. The residue was stirred with ether for $1 \mathrm{~h}$ and filtered off. After washing again with ether, the sample was dried over night in a vacuum oven at $80{ }^{\circ} \mathrm{C}$ resulting in a bright red powder. Yield $0.459 \mathrm{~g}$ $(90 \%)$. Though 32 had no distinct melting point, its color became gradually brown upon approaching $250{ }^{\circ} \mathrm{C}$, while the powder stayed dry and was easily removable from the capillary tube. The absorption spectrum of this heated sample indicated it was partially deacetylated to rose bengal ethyl ester. The sample is charred when heated above $300{ }^{\circ} \mathrm{C}$.

IR $(\mathrm{KBr}) 1780 \mathrm{~cm}^{-1}$ (acetyl C=O), 1730 (ethyl ester $\mathrm{C}=\mathrm{O})$.

UV-Vis $\left(\mathrm{CH}_{2} \mathrm{Cl}_{2}\right) \lambda_{\max }(\log \varepsilon): 494 \mathrm{~nm}(4.03), 395$ (4.22); $\lambda_{\min }(\log \varepsilon): 441 \mathrm{~nm}(3.87)$.

UV-Vis (MeOH) $\lambda_{\max }: 494 \mathrm{~nm}, 400 ; \lambda_{\min }: 447 \mathrm{~nm}$.

The quantity soluble in $\mathrm{MeOH}$ was not sufficient to allow accurate measuring of a quantitative absorption spectrum.

${ }^{1} \mathrm{H}$ NMR $\left(\mathrm{CDCl}_{3}\right) \delta(\mathrm{ppm}): 0.98\left(\mathrm{t},-\mathrm{CH}_{3}, 3 \mathrm{H}\right.$, $J=7.1 \mathrm{~Hz}$ ), $2.48\left(\mathrm{~s}, \mathrm{CH}_{3} \mathrm{C}=\mathrm{O}, 3 \mathrm{H}\right), 4.01$ (quartet, $\left.-\mathrm{CH}_{2}-, 2 \mathrm{H}, J=7.1 \mathrm{~Hz}\right) 7.41(\mathrm{~s}, 1 \mathrm{H}$, xanthene$\mathrm{H}), 7.65(\mathrm{~s}, 1 \mathrm{H}$, xanthene-H).

The synthesis of the eosin derivatives was carried out in complete analogy with those of rose bengal. Their spectral properties have already been mentioned in Table II.

The authors are most grateful to the Petroleum Research Fund, which is administered by The American Chemical Society, for providing funds in support of the work discussed in this paper.
[1] A. Baeyer, Ber. 4, 555, 658 (1871).

[2] O. Raab, Z. Biol. 39, 524 (1900).

[3] H. V. Tappeiner and A. Yodlbauer, Dtsch. Arch. Klin. Med. 80, 427 (1904).

[4] H. Kautsky and H. de Bruijn, Naturwissenschaften 19, 1043 (1931).

[5] A. Windaus and J. Brunken, Ann. 460, 225 (1928).

[6] A. Schonberg, Ann. 518, 299 (1935).

[7] G. O. Schenck, Naturwissenschaften 35, 28 (1948).

[8] G. O. Schenck, Z. Elektrochem. 55, 505 (1951).

[9] K. Gollnick and G. O. Schenck, Pure Appl. Chem. 9, 507 (1964).

[10] Singlet Molecular Oxygen, Benchmark Papers in Organic Chemistry, Vol. 5, A. P. Schaap (ed.), Dowden, Hutchinson and Ross, Inc., Stroudsburg, Pa. (1976), a historical review.

[11] R. W. Denny and A. Nickon, Org. React. 20, 133 (1973).

[12] K. Gollnick, Adv. Photochem. 6, 1 (1968).

[13] Singlet Oxygen, B. Rånby and J. F. Rabek (eds.), Wiley, Chichester (1978).

[14] Singlet Oxygen, H. H. Wassermann and R. W. Murray (eds.), Academic Press, New York (1979).

[15] C. S. Foote and G. Uhde, Org. Photochem. Synth. 1, 60 (1971).

[16] C. S. Foote and G. Uhde, Org. Photochem. Synth. 1, 70 (1971).

[17] M. Imamura and M. Koizumi, Bull. Chem. Soc. Jpn. 28, 117 (1955); ibid. 29, 889 (1956); ibid. 29, 913 (1956).

[18] M. Imamura, Bull. Chem. Soc. Jpn. 30, 249 (1957); ibid. 31, 62 (1958); ibid. 31, 962 (1958).
[19] K. Kimura, T. Miwa, and M. Imamura, Bull. Chem. Soc. Jpn. 43, 1329 (1970); ibid. 43, 1337 (1970).

[20] F. F. Zwicker and L. I. Grossweiner, J. Phys. Chem. 67, 549 (1963).

[21] G. Oster, G. K. Oster, and G. Karg, J. Phys. Chem. 66, 2514 (1962).

[22] P. Hanson, in Adv. Heterocycl. Chem. 27, 61 (1980), A. R. Katritzky and A. J. Boulton (eds.), Academic Press, New York.

[23] I. H. Leaver, Austr. J. Chem. 24, 753 (1971).

[24] K. Maruyama and N. Narita, J. Org. Chem. 45, 1421 (1980).

[25] W. A. Peeples II and J. R. Heitz, J. Liq. Chromatogr. 4, 51 (1981).

[26] E. Gandin, J. Piette, and Y. Lion, J. Chromatogr. 249, 393 (1982).

[27] D. Fompeydie, F. Onur, and P. Levillain, Bull. Soc. Chim. Fr. II 5 (1982).

[28] The Colour Index, 2nd ed. (1956).

[29] H. J. Conn, Biological Staining, 9th ed., R. D. Lillie, ed., The Williams and Wilkins Co., Baltimore (1977).

[30] J. P. Pooler and D. P. Valenzeno, Med. Physics 8, 614 (1981).

[31] M. J. Wade and J. D. Spikes, Photochem. Photobiol. 14, 221 (1971).

[32] G. E. Cohn and H. Y. Tseng, Photochem. Photobiol. 26, 465 (1977).

[33] T. Ito and K. Kobayashi, Photochem. Photobiol. 26, 581 (1977)

[34] M. Kono and M. Kasai, Photochem. Photobiol. 19, 35 (1974).

[35] J. P. Pooler and D. P. Valenzeno, Photochem. Photo- 
biol. 28, 219 (1978); ibid. 30, 491 (1979); ibid. 30, 581 (1979).

[36] D. P. Valenzeno and J. P. Pooler, Photochem. Photobiol. 35, 343 (1982).

[37] W. E. Varnadore (Jr.), R. T. Arrieta, J. R. Duchek, and J.S. Huebner, J. Membr. Biol. 65, 147 (1982).

[38] B. D. Watson and D. H. Haynes, Chem.-Biol. Interactions 41, 313 (1982).

[39] D. S. Hull, K. Green, S. Csukas, and V. Livingston, Biochim. Biophys. Acta 640, 231 (1981).

[40] E. K. Silbergeld, S. M. Andersen, and S. J. Morris, Life Sci. 31, 957 (1982).

[41] T. P. Yoho, J. E. Weaver, and L. Butler, Environ. Entomol. 2, 1096 (1973).

[42] J. R. Broome, M. F. Callaham, and J. R. Heitz, Environ. Entomol. 4, 883 (1975).

[43] J. R. Fondren (Jr.) and J. R. Heitz, Environ. Entomol 7, 843. (1978).

[44] J. R. Fondren (Jr.), B. R. Norment, and J. R. Heitz, Environ. Entomol. 7, 205 (1978).

[45] G. D. Pimprikar, B. R. Norment, and J. R. Heitz, Environ. Entomol. 8, 856 (1979).

[46] G. D. Pimprikar, J. E. Fondren (Jr.), and J. R. Heitz, Environ. Entomol. 9, 53 (1980).

[47] G. D. Pimprikar, B. L. Noe, B. R. Norment, and J. R. Heitz, Environ. Entomol. 9, 785 (1980).

[48] H. Sakurai and J. R. Heitz, Environ. Entomol. 11, 467 (1982)

[49] A. J. Acher and A. Elgavish, Water Res. 14, 539 (1980)

[50] A. J. Acher and I. Rosenthal, Water Res. 11, 557 (1977).

[51] M. Halmann and D. Levy, Photochem. Photobiol. 30, 143 (1979).

[52] E. Gandin, Y. Lion, and A. Van de Vorst, Photochem. Photobiol. 37, 271 (1983).

[53] W. R. Orndorff and A. J. Hemmer, J. Am. Chem. Soc. 49, 1272 (1927).

[54] V. Zanker and W. Peter, Chem. Ber. 91, 572 (1958).

[55] K. K. Rohatgi and A. K. Mukhopadhyay, Photochem. Photobiol. 14, 551 (1971).

[56] K. K. Rohatgi and A. K. Mukhopadhyay, Chem. Phys. Lett. 12, 259 (1971).

[57] K. K. Rohatgi and A. K. Mukhopadhyay, J. Indian. Chem. Soc. 49, 1311 (1972).

[58] K. K. Rohatgi and A. K. Mukhopadhyay, J. Phys. Chem. 76, 3970 (1972).

[59] L. López Arbeloa, J. Chem. Soc., Farad. Trans. 2, 77, 1725 (1981).
[60] L. López Arbeloa, J. Chem. Soc., Farad. Trans. 2, 77, 1735 (1981)

[61] L. López Arbeloa, J. Photochem. 18, 161 (1982).

[62] H. Leonhardt, L. Gordon, and R. Livingston, J. Phys. Chem. 75, 245 (1971).

[63] G. Guyot, R. Arnaud, and J. Lemaire, J. Chim. Phys. 72, 647 (1975).

[64] V. I. Yuzhakov, Russ. Chem. Rev. 48, 1076 (1979). A general review on dye aggregation.

[65] M. M. Martin and L. Lindqvist, J. Lumin. 10, 381 (1975).

[66] M. M. Martin and L. Lindqvist, Chem. Phys. Lett. 22, 309 (1973)

[67] M. M. Martin, Chem. Phys. Lett. 35, 105 (1975); ibid. 43, 332 (1976).

[68] F. M. Abdel-Halim, R. M. Issa, M. S. El-Ezaby, and A. A. Hasanein, Z. Phys. Chem. N. F. 73, 59 (1970).

[69] I. M. Issa, R. M. Issa, and M. M. Ghoneim, Z. Phys. Chem. (Leipzig) 250, 161 (1972).

[70] R. M. Issa, M. M. Ghoneim, K. A. Idriss, and A. A. Harfoush, Z. Phys. Chem. N. F. 94, 135 (1975).

[71] R. Markuszewski and H. Diehl, Talanta 27, 937 (1980).

[72] R. S. Osborn and D. Rogers, Acta Crystallogr. B31, 359 (1975)

[73] J.-P. Dubost, J.-M. Léger, J.-C. Colleter, P. Levillain, and D. Fompeydie, C. R. Acad. Sci., Paris 292, 965 (1961).

[74] S.-C. Chen, H. Nakamura, and Z. Tamura, Chem. Pharm. Bull. 27, 475 (1979).

[75] D. Fompeydie, F. Onur, and P. Levillain, Bull. Soc. Chim. Fr. I, 375 (1979).

[76] D. Fompeydie, A. Rabaron, P. Levillain, and R. Bourdon, J. Chem. Res. (S) 1981, 350 and (M) 1981, 4052.

[77] D. Fompeydie and P. Levillain, Bull. Soc. Chim. Fr. I, 459 (1980).

[78] A. P. Schaap, A. L. Thayer, E. C. Blossey, and D. C. Neckers, J. Am. Chem. Soc. 97, 3741 (1975).

[79] S. Tamagaki, C. E. Liesner, and D. C. Neckers, J. Org. Chem. 45, 1573 (1980)

[80] K. Nakanishi and P. H. Solomon, Infrared Absorption Spectroscopy, 2nd ed., Holden-Day Inc., San Francisco (1977).

[81] G. B. Deacon and P. W. Felder, Austr. J. Chem. 20, 1587 (1967).

[82] C. D. Hurd and L. Schmerling, J. Am. Chem. Soc. 59, $112(1937)$

[83] L. L. Melhado, S. W. Peltz, S. P. Leytus, and W. F. Mangel, J. Am. Chem. Soc. 104, 7299 (1982). 